\title{
BENEFICIAL EFFECTS OF STINGING NETTLE SUPPLEMENTATION ON MILK PRODUCTION
}

\author{
D.R. Khanal ${ }^{1 *}$, I. Tiwari ${ }^{2}$, R. Bastola ${ }^{3}$ and C. R.Upreti ${ }^{4}$ \\ ${ }^{1}$ Animal Health Research Division, Nepal Agricultural Research Council, Nepal \\ ${ }^{2}$ Himalayan College of Agricultural Sciences and Technology (HICAST), Kathmandu \\ ${ }^{3}$ Animal Nutrition Division, NARC, Nepal \\ ${ }^{4}$ Livestock and Fisheries Research Directorate, NARC, Nepal \\ (*email: drkhanal7@gmail.com)
}

\begin{abstract}
After having demonstrated the beneficial effects of stinging nettle supplementation in poultry and pigs, a month long on-station pilot trial in 10 lactating cattle of second to third stage of parity at CattleResearch Programme at Nepal Agricultural Research Council, Lalitpur was carried out. Daily supplementation of 20 gm nettle powder to dairy cattle resulted in enhanced milk production by 0.9 litres on an average compared to milk yield before nettle supplementation (3.2 litres/day versus 4.1 litres/day). After the onstation pilot trial; an on-farm trial in Tanahun, $150 \mathrm{~km}$ west of Kathmandu was carried out in 12 lactating Jersey cross cows by daily supplementation of $20 \mathrm{gm}$ (T1) and $40 \mathrm{gm}$ (T2) of nettle powder in two groups ( $n=4$ cows/group) of cattle and productive performance was compared with control. Milk yield in terms of quantity and quality was recorded one week prior and during nettle supplementation. Qualitative analysis of milk samples was done every 14 days to measure levels of milk fat, solid non-fat and milk protein using Lactoscan. Available data on on-farm trial showed that there was increment in milk production in both treatment (T1 and T2) groups by $8.08 \%$ and $10.19 \%$, respectively against control. Similarly, fat percentage was also increased compared to fat level prior to nettle supplementation in both $T 1(3.52 \%$ vs. $4.15 \%)$ and $T 2(3.46 \%$ vs. $4.46 \%)$ groups while in control group there was very negligible change $(3.24 \%$ vs. $3.33 \%$ ). Likewise, there were also remarkable increment in solid non-fat (SNF) and milk protein in nettle fed groups against control. Furthermore, overall body condition score in nettle supplemented group was better than that of control towards the end of supplementation. Our findings exhibited the beneficial effects of stinging nettle supplementation in enhancing the quantity and quality milk yield besides improving body condition score of the dairy cattle.
\end{abstract}

Keywords: stinging nettle, milk yield, milk quality, body condition score

\section{INTRODUCTION}

In the recent years, various efforts, ranging from the use of milk formula to bovine somatotrophin (BST) hormone or bovine growth hormone (BGH) have been used by the researchers and farmers to enhance milk yield in dairy animals. Use of BST is debated across the globe; it is legal in USA while it is not in Europe (Global Healing Center, 
2014). The commercial milk formula consisting especially of Calcium, Phosphorus and Vitamins A, D and E in oral liquid form is quite popular in the peri-urban households of Nepal. However, such commercial formula involves cost and thereby reduction in the net profit from the sale of milk. Some subsistence farmers in the hills and mountains of Nepal feed nettle (Urtica dioica) gruels to their lactating animals with the perception of getting more milk yield with higher level of ghee (clarified butter) without any scientific backing. The current study was aimed at scientific validation of beneficial effect of nettle supplementation and creating awareness among producers and consumers about organic way of milk production using locally available natural resource that goes wasted in rural areas.

Few years earlier, supplementations of stinging nettle powder in poultry and cooked preparation in pigs demonstrated beneficial effects in terms of productive performances (Khanal, 2008; 2009; 2015). Egg laying performance was enhanced up to $35 \%$ in poultry in addition to improved growth and carcass quality in nettle-supplemented group. Furthermore, antibody titre against New Castle disease was maintained at a protective level in nettle-supplemented group when compared to control. The egg yolk appeared very intact and appealing even after storage at room temperature for 4 weeks in nettle supplemented group. Similarly, the crude protein percent was higher in broiler carcass supplemented with nettle.

Similar study conducted at Agricultural Research Station, Dhankuta, Nepal in piglets revealed the growth performance of nettle feeding at 30\% inclusion level as compared to control, receiving only commercial ration. Encouraged by the results in pig and poultry, we wanted to investigate the effect of nettle supplementation in milk yield and its quality, both at on station and on farm. This paper discusses about the results of a pilot test at the National Bovine Research Programme, Khumaltar, NARC and that of on-farm trial in farmers' field at Tanahun.

\section{MATERIALS AND METHODS}

\section{Preparation of nettle powder}

Young, immature leaves of nettle were collected from Dhading and Tanahun districts and dried in shade for 3-4 days. Nettle powder was prepared using a blender. About $18 \mathrm{~kg}$ of nettle powder was prepared for supplementation in cattle and stored appropriately in a cool and dry place.

\section{On-station trial (Experiment I)}

A total of 10 cattle of similar age and parity of Bovine Research Programme, Khumaltar were divided into two groups: treatment $(n=5)$ and control $(n=5)$. All cattle were dewormed with 3-4 boli of Oxyclozanide hydrochloride depending on the body weight one day prior to nettle supplementation. Lactating cows of treatment group received daily supplementation of $20 \mathrm{gm}$ nettle powder in the commercial concentrate feed during the evening while control received only the commercial concentrate feed for 21 days. Maintenance and production ration were given to all cattle as per their milk yield. The daily milk was recorded one week prior to supplementation until the end of experiment. Experiment lasted 3 weeks. Milk was assessed qualitatively for fat $\%$, Solid non-fat (SNF) 
$\%$, milk protein $\%$ and conductivity using Lacto-scanner before and after nettle supplementation.

\section{On-farm trial (Experiment II)}

Inspired by the positive result of the on-station pilot testing, further investigation with onfarm testing was carried out at Pokhari Bhanjhyang Village Development Committee (VDC), of Tanahun district in Year 2012 with two levels of nettle supplementation (T1: 20 gm and T2: 40 gm daily for 60 days). A total of 12 crossbred Jersey cattle was selected with similar age, lactation and parity (2-4) and divided into three groups (by purposive sampling) consisting of two treatments: T1 $(n=4), T 2(n=4)$ and one control $(n=4)$. All cattle were kept in similar management. Lactating cows of treatment groups-T1 and T2 received daily supplementation of $20 \mathrm{gm}$ and $40 \mathrm{gm}$ nettle powder, respectively for 60 days in the concentrate feed in the morning while control (T0) received only the concentrate feed. Their daily milk yield was recorded from one week prior to supplementation until the end of experiment. Body condition score (BCS) was recorded prior to nettle supplementation and at the end of 60 days trial. Milk was assessed from all three groups qualitatively for fat $\%$, solid non-fat (SNF) and milk protein using Lactoscanner every two weeks and compared.

\section{Statistical calculations}

The statistical calculations were limited to the determination of the mean value of the parameters of milk quantity (Milk Yield) and quality (Fat\%, SNF\%, Protein\% and Conductivity) in both on-station and on-farm trials. The standard error of the mean was calculated for each of the parameters and means were compared Tukey MSD (IBM SPSS Statistics Version 23).

\section{RESULTS AND DISCUSSIONS}

\section{Experiment I (On-station trial)}

On an average there was significant increment $(\mathrm{p}<0.042)$ in milk yield by $400 \mathrm{ml}$ after nettle supplementation ( $4100 \mathrm{ml} /$ day) compared to milk yield before $(3700 \mathrm{ml} /$ day $)$ nettle supplementation. In control group, the milk yield remained unchanged (slightly decreased) when compared to nettle supplemented group (Fig. 1).

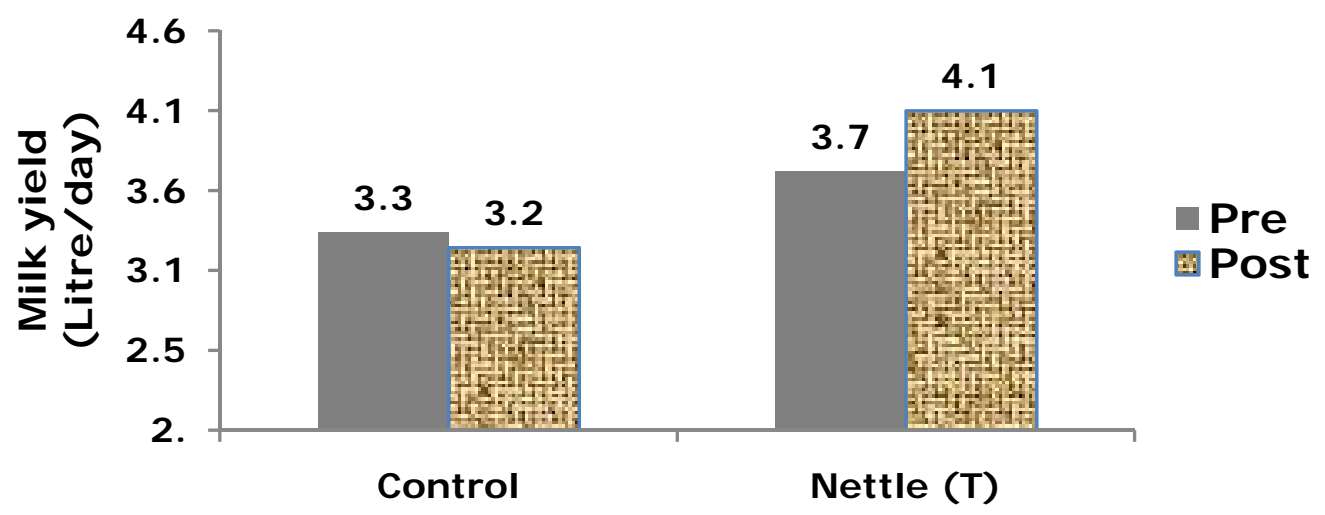

Fig. 1: Showing productive performance of nettle supplemented cattle against control receiving only commercial ration 


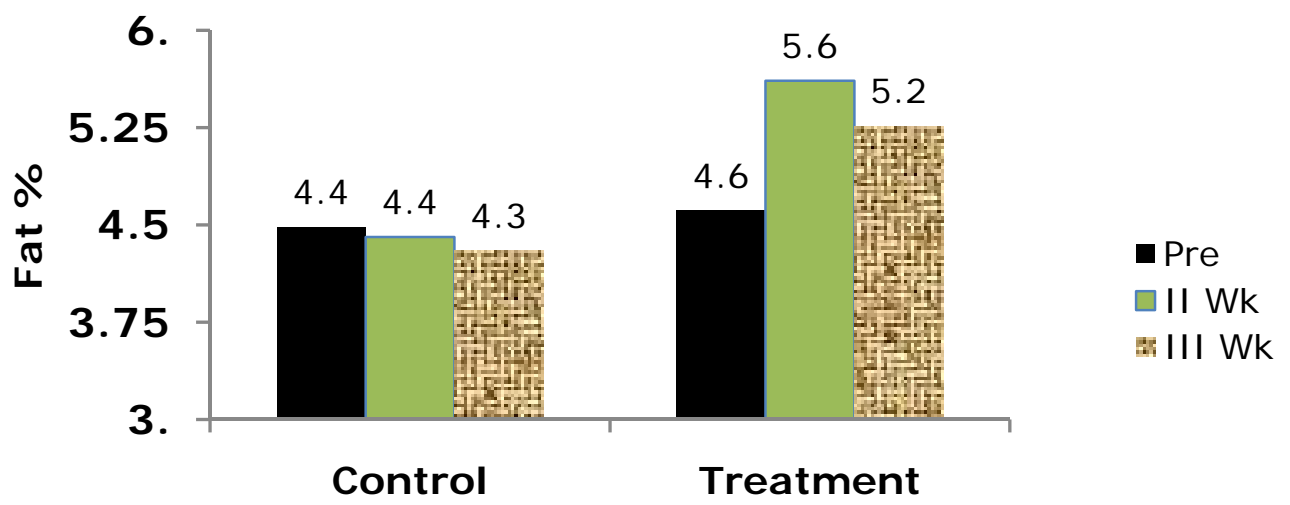

Fig.2: Showing the effect of nettle supplementation (Treatment) on milk fat $\%$ in two groups of cattle

Similarly, there was increment in fat percentage in milk of nettle supplemented group (Fig. 2) when compared to that of control. Milk fat rose from $4.61 \%$ to $5.61 \%$ level two weeks after nettle supplementation in treatment group whereas it did not change in control. Contrary to the general expectation, there were no remarkable differences in $\mathrm{SNF} \%$, protein\% and conductivity in milk samples in both groups before and during nettle supplementation (Figs. 3-5).

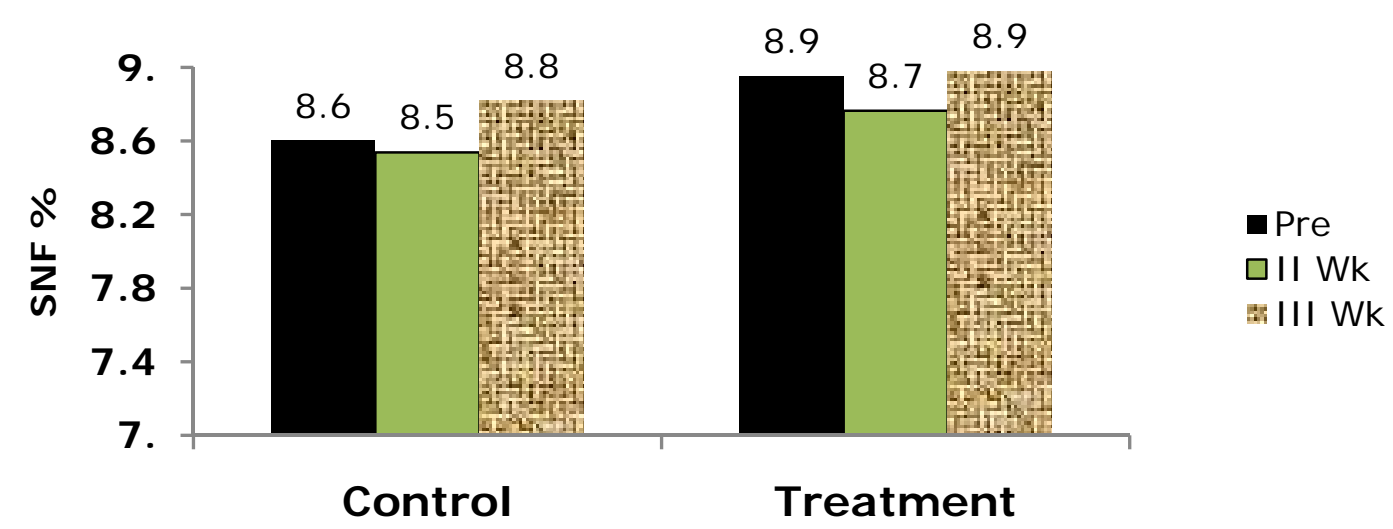

Fig. 3: Showing the level of Solid Non-Fat (SNF) \% in milk of cattle supplemented with nettle (Treatment) and without nettle (Control). 


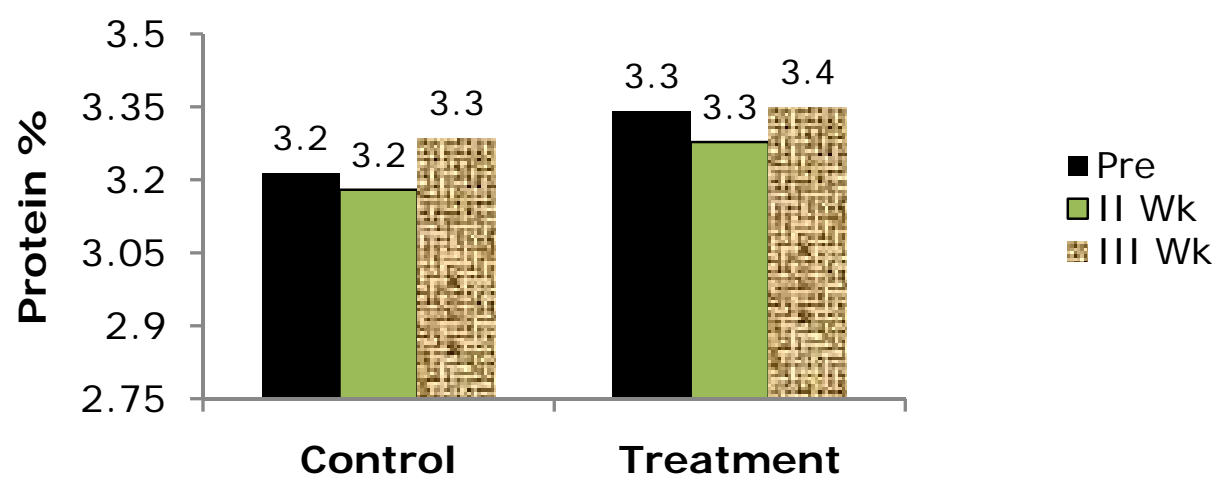

Fig. 4: Showing the level of protein $\%$ in milk of cattle supplemented with nettle (Treatment) and without nettle (Control).

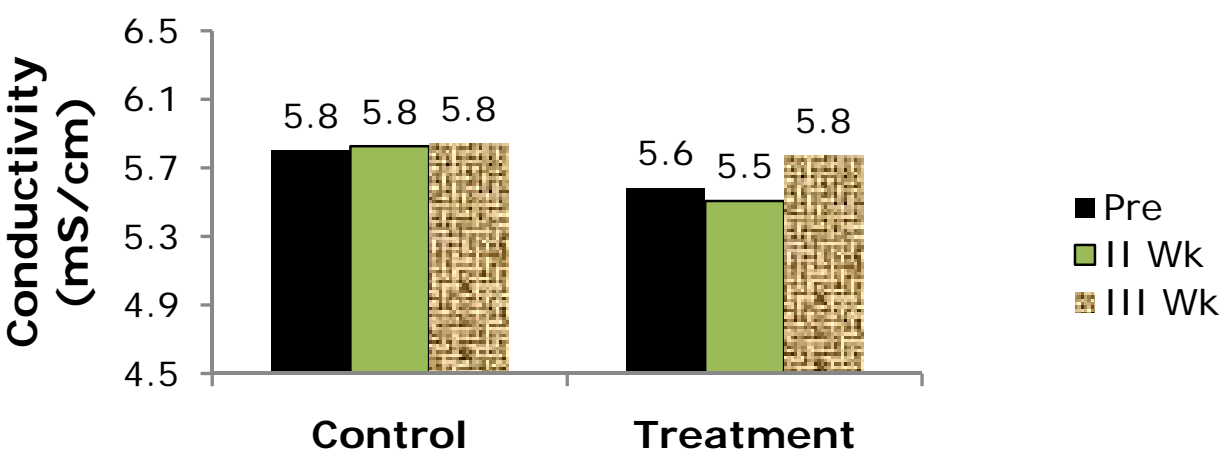

Fig. 5: Showing the conductivity in milk of cattle supplemented with nettle (Treatment) and without nettle (Control)

\section{Experiment 2 (On-farm trial)}

Results of nettle supplementation at two levels were encouraging for all parameters: adjusted average daily milk yield increment were $940 \mathrm{ml}$ in $\mathrm{T} 1$ and $1900 \mathrm{ml}$ in T2 compared to control (C). Similarly, adjusted increments in milk fat $\%$ compared to control were $0.54 \%$ and $0.91 \%$; milk protein were $0.07 \%$ and $0.09 \%$ and SNF were $0.16 \%$ and $0.25 \%$, respectively in $\mathrm{T} 1$ and $\mathrm{T} 2$ groups. BCS also improved by $7 \%$ and $10 \%$, respectively in T1 and T2 groups (Figs. 6-10). 


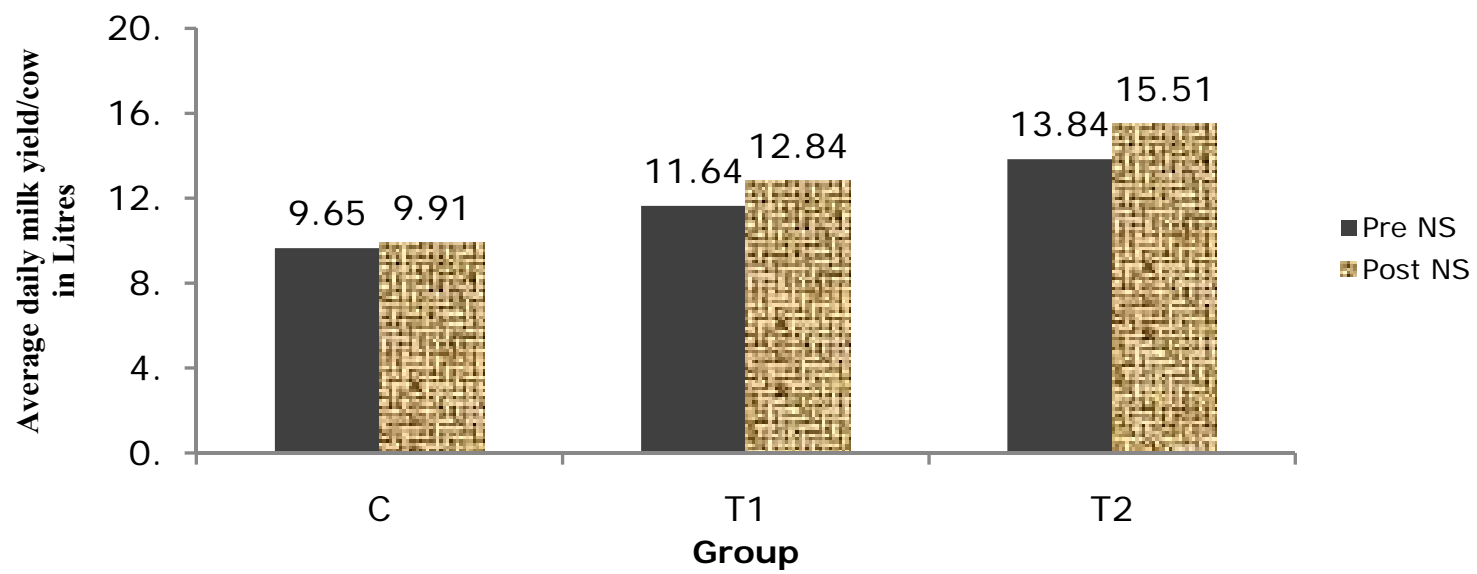

Fig. 6: Showing comparison of milk yield in litres (L) before (7 days) and after nettle supplementation (NS) in control (C) and nettle supplemented groups (T1: $20 \mathrm{gm} /$ day and $\mathrm{T} 2: 40 \mathrm{gm} /$ day for 60 days)

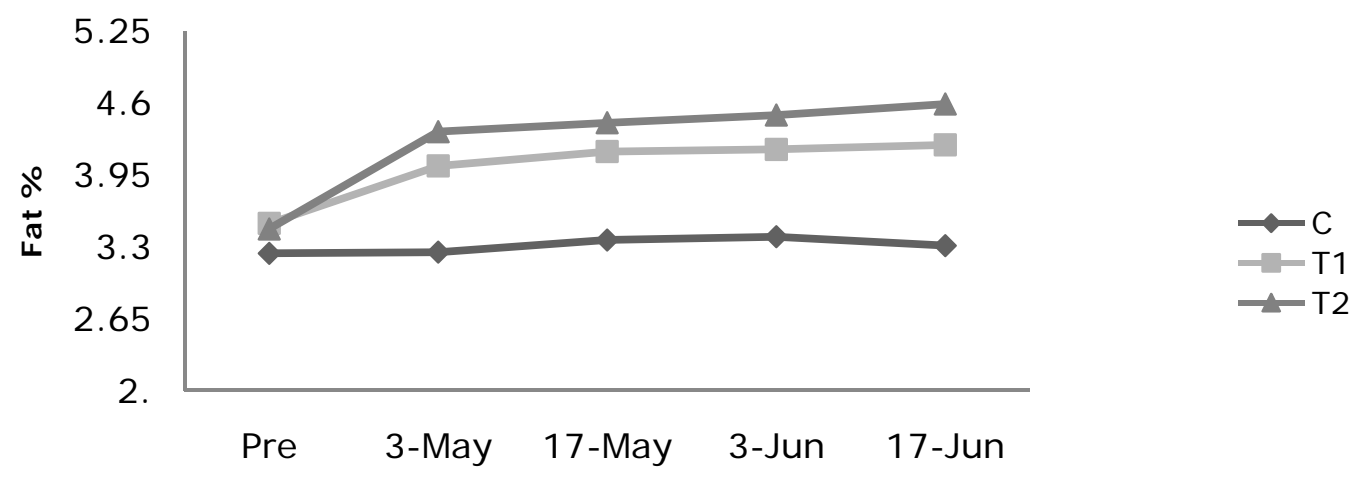

Fig. 7a: Showing temporal comparison of fat $\%$ in treatment $(\mathrm{T} 1=20 \mathrm{gm} /$ day and $\mathrm{T} 2=40$ $\mathrm{gm} /$ day) and control (C) cattle before and after nettle supplementation (NS).

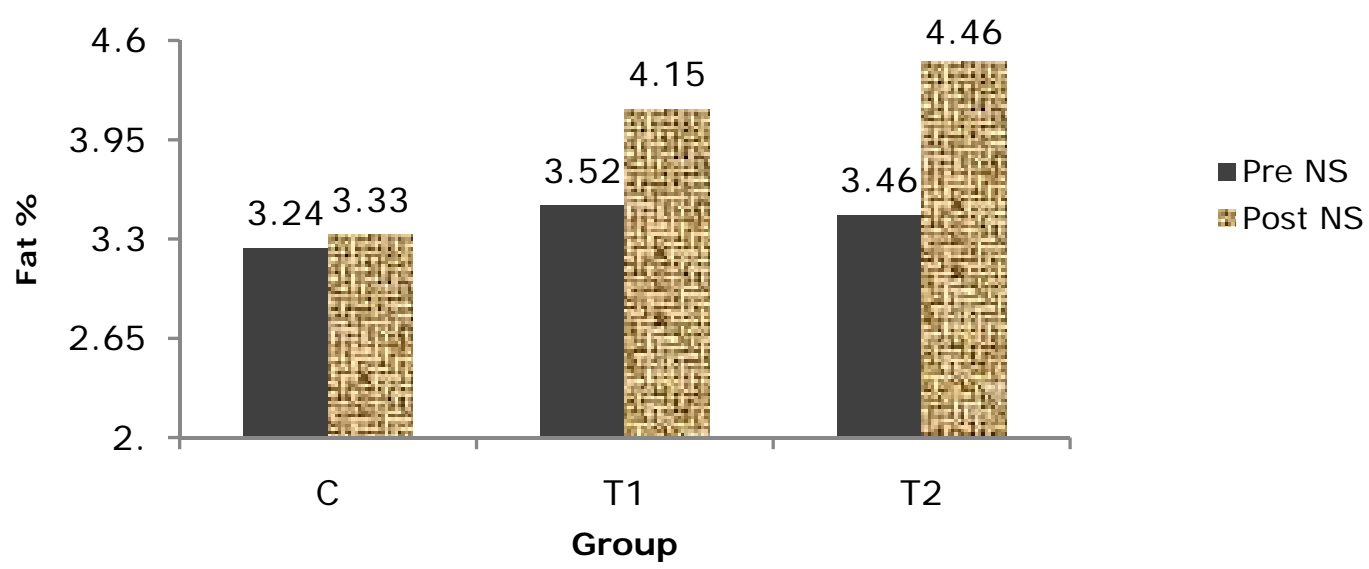

Fig. 7b: Showing comparison of average fat $\%$ in treatment $(\mathrm{T} 1=20 \mathrm{gm} /$ day and $\mathrm{T} 2=40$ $\mathrm{gm} /$ day) and control (C) cattle before and after nettle supplementation (NS) for 60 days. 


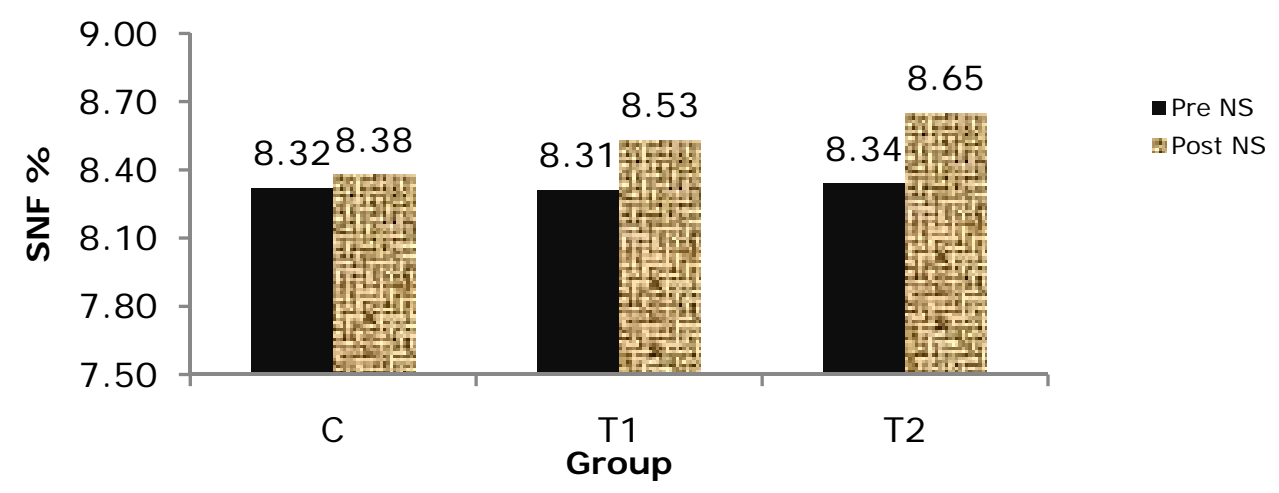

Fig. 8: Showing comparison of solid non-fat (SNF) \% in control (C) and treatment $(\mathrm{T} 1=20$ $\mathrm{gm} /$ day and $\mathrm{T} 2=40 \mathrm{gm} /$ day) groups before and after nettle supplementation (NS)

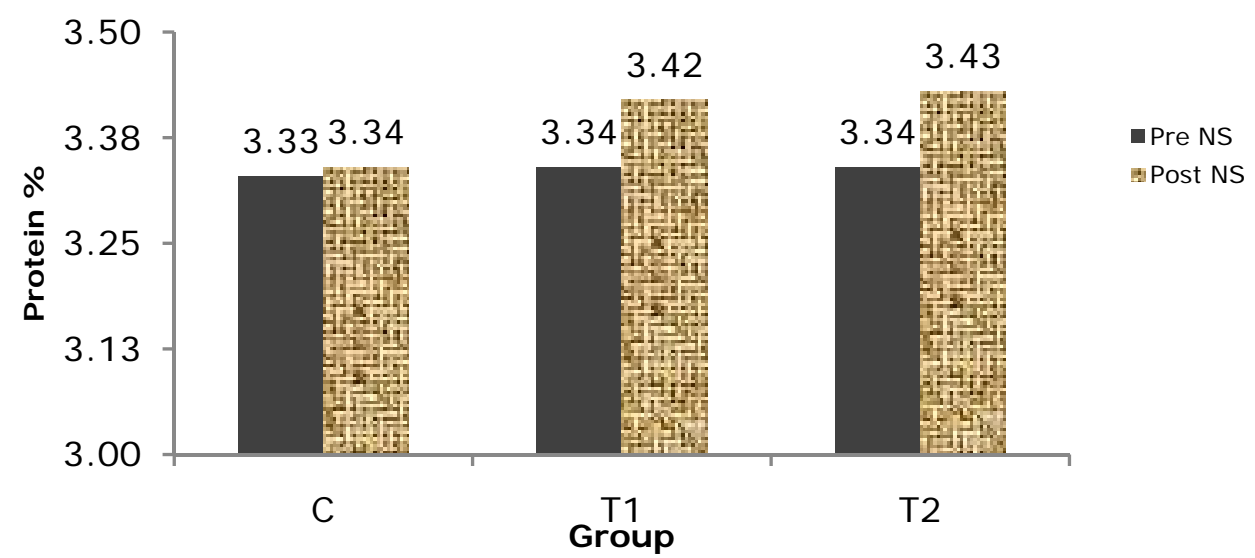

Fig. 9: Showing comparison of milk protein $\%$ in control (C) and treatment (T1=20 $\mathrm{gm} /$ day and $\mathrm{T} 2=40 \mathrm{gm} /$ day) groups before and after nettle supplementation (NS)

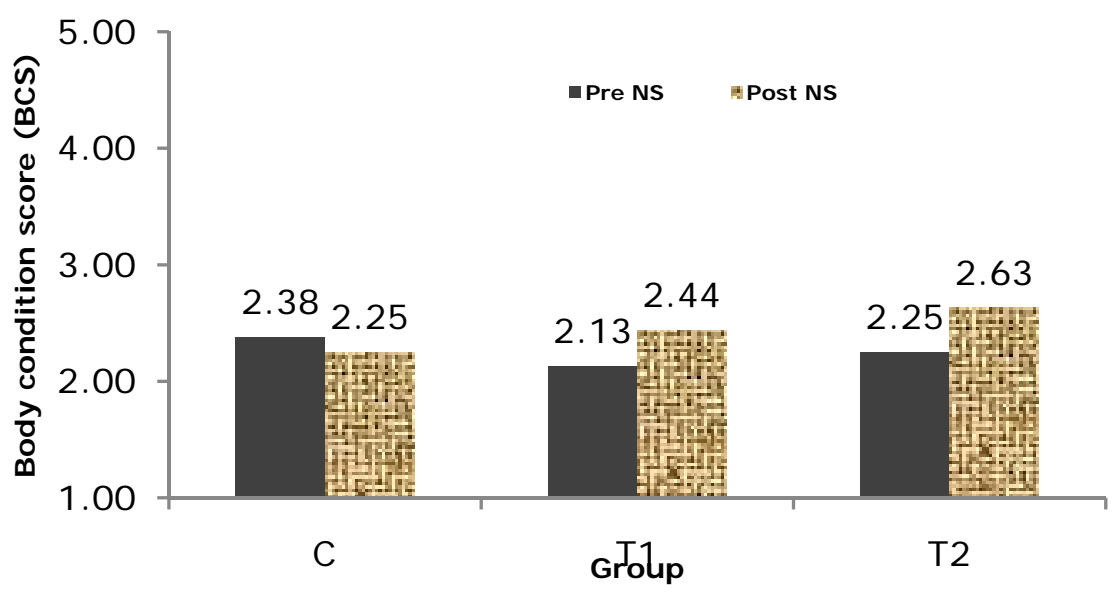

Fig. 10: Showing comparison of body condition score (BCS in 1-5 Scale) in control (C) and treatment $(\mathrm{T} 1=20 \mathrm{gm} /$ day and $\mathrm{T} 2=40 \mathrm{gm} /$ day) groups before and after nettle supplementation (NS) 
After nettle supplementation in both $\mathrm{T} 1$ and $\mathrm{T} 2$ groups, rise in average fat \% (Figs. 7a and $7 \mathrm{~b}$ ) was obvious. As expected, there has been enhancement of milk quality in terms of SNF\% and protein\% in both nettle supplemented groups (Figures 8 and 9). Similarly, the body condition score of cow improved in nettle supplemented groups. The on-farm results have clearly indicated that nettle supplementation has the potential to enhance productive performance in dairy cattle not only by increasing the milk quantity but also by improving the quality besides exerting positive effect on body condition score. Furthermore, economic analysis revealed that extra profit Rs. 15,410 (US \$ 200) was generated from increased milk yield, fat $\%$ and SNF\% in top of regular sale of milk to the cooperative. In line with earlier studies in poultry (Khanal et al., 2008; Maharjan, 2008; Regmi, 2010; Poudel and Khanal, 2011; Dahal and Khanal, 2012; Khanal et al., 2015) this study has proved that nettle supplementation is beneficial for imparting positive effects towards organic production of milk among dairy farmers especially in rural areas where stinging nettle is abundantly available with virtually low labour cost towards in collecting and processing.

Considering the cost and availability of nettle powder, the optimum dose would be 20-40 gm day although toxic level not has been established. Since nettle powder is rich in nonspecific nutrients such as Vitamins E and C, Calcium, Phosphorus, Iron and lectins, its supplementation will directly enhance the milk production besides boosting up the immunity in animals. Although in vivo anti-parasitic effect in pig was not seen, but it needs to be studied in cattle.

\section{ACKNOWLEDGEMENT}

The authors are thankful to the staff of Animal Health Research Division and then Bovine Research Programme of Nepal Agricultural Research Council (NARC) for their support.

\section{REFERENCES}

Dahal, M. and Khanal, D.R. (2012). Study on the effect of stinging nettle (Urtica dioica) on productive performance of layer chicken. In: Proceedings of the $10^{\text {th }}$ National Veterinary Conference of Nepal Veterinary Association, Kathmandu, Nepal, Pp. 265-270.

Global Healing Centre (2014). 8 Shocking Facts about Bovine Growth Hormone. In: http://www.globalhealingcenter.com/natural-health/8-shocking-facts-bovinegrowth-hormone.

Khanal, D.R., Piya, B, Gautam, K., Acharya, M.P., Singh, U.M. and Knight, A.P. (2008). Stinging nettle as an ovogogue and immunomodulator in poultry. In: Proceedings of the XXIII World's Poultry Congress, held at Brisbane, Australia(June 30-July 4, 2008). (Abstract: pp. 338 and full paper on CD Rom).

Khanal, D.R., Dhungana, K.P., Thakur, R.P., Yadav, M., Mukhiya, Y.L. and Shrestha, S. (2009). Nettle (Urtica dioica) feeding for augmenting growth performance and carcass quality of pigs. In: Proceedings of the $7^{\text {th }}$ National Workshop on Livestock and Fisheries Research held at Khumaltar, Lalitpur, Nepal (June 25-27, 2007), Pp. 219-222. 
Khanal, D.R., Regmi, P., Paudel, N., Gautam, D., Dahal, U., Haldar, S and Creswell, D. (2015). In: Abstract Book of the $10^{\text {th }}$ National Livestock and Fisheries Workshop.

Maharjan, R. (2008). Study on the immunomodulatory property of Sisno (Urtica dioica). Mini Thesis, HICAST, Purbanchal University, Nepal.

Poudel, N. and Khanal, D.R. (2011). Effect of stinging nettle feeding on productivity and immune response in laying hens. Nepalese Veterinary Journal, 30: 51-58.

Regmi, P. (2010). Supplementation of nettle in broiler parent diet and its effect on productive performance. Mini-thesis, Institute of Agriculture and Animal Science, TU, Rampur, Nepal. 